\title{
Vascular endothelial growth factor and soluble vascular endothelial growth factor receptor-1 in patients with end- stage renal disease
}

\author{
Associations with laboratory findings, comorbidities, and medications
}

Ismail Erturk, MD, PhD, Fatih Yesildal, MD, PhD, Ramazan Acar, MD, PhD, Taner Ozgurtas, MD, Kenan Saglam, MD.

\section{ABSTRACT}

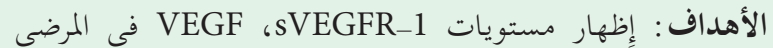

الذين يعانون من الداء الداء الكلوي بمريتواحله الأخيرة (ESRD) و وإظهار

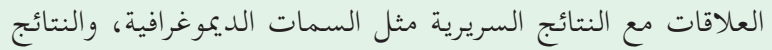

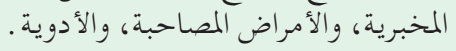

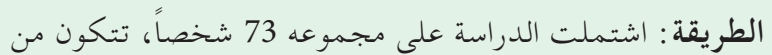

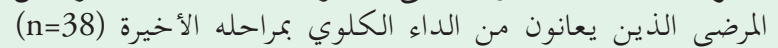

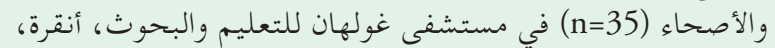

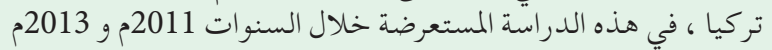

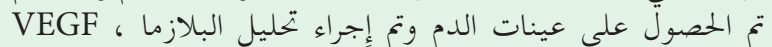
sVEGFR_1

النتائج: لم يكن مستوى VEGF لمجموعة ESRD أعلى

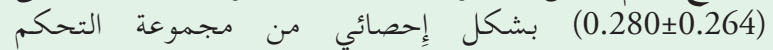

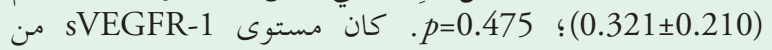

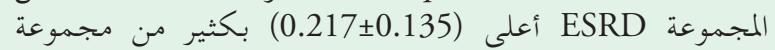

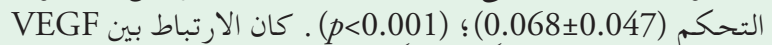

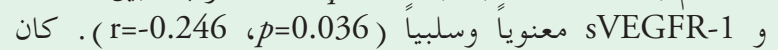
متوسط مستوى لم لمرضى الداء الكلوي بمراحله الأخيرة

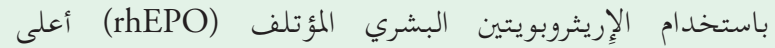

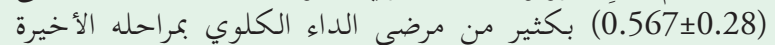

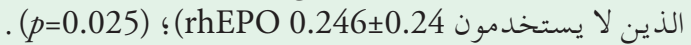

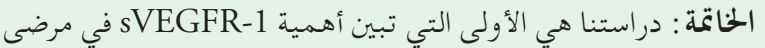

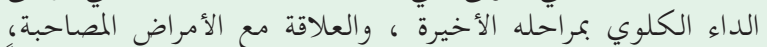

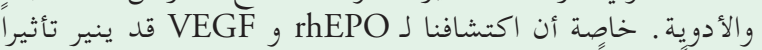

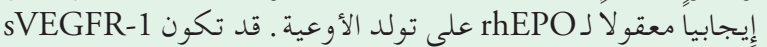

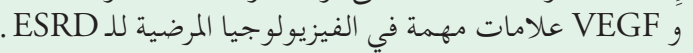

Objectives: To show the levels of vascular endothelial growth factor (VEGF), soluble vascular endothelial growth factor receptor-1 (sVEGFR-1) in patients with end-stage renal disease (ESRD) and to show the associations with clinical findings such as demographic features, laboratory findings, comorbidities, and medications.
Methods: A total of 73 people, consisting of patients with ESRD $(n=38)$ and healthy subjects $(n=35)$ in Gulhane Education and Research Hospital, Ankara, Turkey, were included in this cross-sectional study between the years 2011 and 2013. Blood samples were obtained and plasma VEGF, sVEGFR-1 analyzes were performed.

Results: The VEGF level of ESRD group was not significantly higher $(0.280 \pm 0.264)$ than the control group $(0.321 \pm 0.210) \quad(p=0.475)$. The $s$ VEGFR-1 level of ESRD group was significantly higher $(0.217 \pm 0.135)$ than the control group $(0.068 \pm 0.047) \quad(p<0.001)$. The correlation between VEGF and sVEGFR-1 was significant and negative $(r=-0.246, p=0.036)$. Average VEGF level of ESRD patients using recombinant human erythropoietin (rhEPO) was significantly higher $(0.567 \pm 0.28)$ than the ESRD patients not using rhEPO $(0.246 \pm 0.24)(p=0.025)$.

Conclusion: Our study is the first showing the significance of sVEGFR-1 in ESRD patients, and associations with comorbidities, medications. Especially our finding of rhEPO and VEGF may illuminate a reasonable positive effect of rhEPO on angiogenesis. Soluble vascular endothelial growth factor receptor-1 and VEGF may be important markers in the pathophysiology of ESRD.

Saudi Med J 2018; Vol. 39 (6): 586-591 doi: 10.15537/smj.2018.6.22024

From the Department of Internal Medicine (Erturk, Acar, Saglam), Department of Biochemistry (Ozgurtas), University of Health Sciences, Gulhane Education and Research Hospital, Ankara, and Department of Medical Biochemistry (Yesildal), Istanbul Medeniyet University, Goztepe Education and Research Hospital, Istanbul, Turkey.

Received 16th June 2018. Accepted 25th April 2018

Address correspondence and reprint request to: Dr. Ismail Erturk, Department of Internal Medicine, University of Health Sciences, Gulhane School of Medicine, Etlik, Ankara, Turkey. E-mail: ierturk@hotmail.com ORCID ID: https://orcid.org/0000-0001-6835-0988 
T he term "end-stage renal disease" (ESRD) usually refers to chronic kidney disease (CKD) treated with either dialysis or transplantation. For the exact definition of ESRD, the estimated glomerular filtration rate (eGFR) is $<15 \mathrm{~mL} /$ minute $/ 1.73 \mathrm{~m}^{2} .^{1-3}$ Vascular endothelial growth factor (VEGF) is a prominent growth factor that is responsible for the angiogenic process in the kidneys. ${ }^{4-6}$ The VEGF was formerly thought to be an angiogenic molecule that both supported blood vessel dilation and provided new blood vessel formation. The majority of VEGF receptors are VEGF receptor-1 (VEGFR-1) and VEGFR-2, which are transmembrane proteins. Soluble vascular endothelial growth factor receptor-1 is mainly found on endothelial cells and monocytes. Soluble vascular endothelial growth factor receptor-1-mediated signaling is an important action, as it increases vascular permeability. ${ }^{7.8}$ In pathological conditions like ESRD, extreme VEGF production may cause new vessel formation; this condition may destroy the tissue and organ structure. Soluble vascular endothelial growth factor receptor-1 (sVEGFR-1) is produced by alternative splicing of VEGFR-1 mRNA. It acts as a decoy peptide, and it is likely that it negatively regulates VEGF. Its levels correlate with prognosis; it is a severe sign of disease intensity in the intensive care unit (ICU) patients. ${ }^{9} 10$ Sufficient release of VEGFR-1 can be crucial in preventing exaggerated angiogenesis, and it contributes to the remodeling process of ESRD.

However, studies reporting the association among circulating VEVGF, sVEGFR-1 levels and clinical information of patients with ESRD are very limited. In this study, we hypothesized that circulating sVEGFR-1 and VEGF would be clinically important in hemodialysis (HD) patients. We tested this hypothesis in $38 \mathrm{HD}$ patients by evaluating their clinical features such as the medications they used and their comorbidities.

Methods. A total of 73 participants, including patients with ESRD ( $\mathrm{n}=38)$ and healthy subjects $(\mathrm{n}=35)$, attending Gulhane Education and Research Hospital, Ankara, Turkey were included in this comparative crosssectional study between 2011 and 2013.

All of the participants gave their informed consent. The local ethics committee of Gulhane Education and Research Hospital approved this study protocol. All of

Disclosure. Authors have no conflict of interests, and the work was not supported or funded by any drug company. the procedures that we followed were in accordance with the ethical standards of the respective committees on human experimentation (institutional and national) and with the Helsinki Declaration of 1975, as revised in 2008. Every members of the ESRD group and control group were older than 18. All of the patients underwent $\mathrm{HD} 3$ times per week (3-5 hours per session) using bicarbonate dialysate and high-flux (22\%) or low-flux $(72 \%)$ dialysis membranes. Any patients with infections, acute or chronic inflammatory disease, cerebrovascular occlusion, high sedimentation rate, or C-reactive protein with malignancy were excluded from the study. Serum VEGF and sVEGFR-1 levels were measured using Quantikine ELISA kits (R\&D Systems, Minneapolis, MN, USA) and a Synergy HT plate reader (Bio-Tek Instruments Inc, Winooski, VT, USA). All of the patients' clinical features, medical history, medication regimens, and laboratory results were recorded and compared.

The Statistical Package for the Social Sciences for Windows, Version 16.0 (Chicago, SPSS Inc.) was used for the data analysis. For the descriptive statistics, discontinuous variables were demonstrated as numbers and percentages (\%); continuous variables were demonstrated as mean \pm standard deviation. The Kolmogorov-Smirnov test was used to measure the normality of the data. A chi-square test was used to evaluate the relationships among the independent variables. Student's t-test was used to evaluate the difference between the averages of the 2 groups for continuous variables with normal distributions. The Mann-Whitney U test was used to evaluate the difference between the averages of the 2 groups for continuous variables without normal distribution. A $p$-value $<0.05$ was considered to be significant.

Results. The average ages and body mass indexes (BMIs) of the patient and control groups were similar and were not significantly different from each other (Table 1). In the ESRD group, 7 of the patients had coronary artery disease (CAD), 22 had hypertension (HT), and 12 had heart failure (HF). The healthy control group had no chronic disease or medication (Table 2). The laboratory results and demographic features of patients were assessed. The white blood cell (WBC) count, urea, creatinine, hemoglobin, eGFR, alanine aminotransferase (ALT), albumin, high-density lipoprotein-cholesterol (HDL-C), parathormone (PTH), uric acid, calcium, phosphor, magnesium, and ferritin levels of patients and the control group were significantly different (Table 1) $(p<0.05)$. Mean VEGF level of all ESRD patients was not significantly different 
from the control group while the mean sVEGFR-1 level of all HF patients was significantly higher $(p=0.475)$ than the control group $(p<0.001)$ (Table 1). Mean VEGF levels of ESRD patients with CAD, HF, and HT were not significantly different from the ESRD patients without any accompanying disease and the control group. Mean sVEGFR-1 levels of the ESRD patients with CAD, HF, and HT were significantly different from the control group but were not significantly different from the ESRD patients without an accompanying disease (Table 2).

Average VEGF level of ESRD patients using recombinant human erythropoietin (rhEPO) was significantly higher than the ESRD patients not using rhEPO (Table 2). Average VEGF level of ESRD patients using insulin was significantly lower than the ESRD patients not using insulin (Table 2). Average sVEGFR-1 level of ESRD patients using calcium channel blocker (CCB) was significantly lower than the ESRD patients not using CCB. Average sVEGFR-1 level of ESRD patients using beta blockers, acetylsalicylic acid, enoxaparin, CCB, rhEPO, and insulin were significantly different from the healthy control group (Table 2).

Discussion. In the present study, we have investigated putative links of VEGF and its soluble receptor sVEGFR-1 in prevalent HD patients. We have aimed to evaluate the levels and clinical significance of VEGF and sVEGFR-1 (relationships between VEGF and sVEGFR-1 with demographics, laboratory findings, co-morbidities, and medications) in patients on HD treatment.

We have found the level of sVEGFR-1 higher than the control group due to inflammation likely to the previous studies. ${ }^{11}$ Also, according to the literature, an increased level of sVEGFR-1 is an independent risk factor for CKD, which causes low prognosis and high cost. ${ }^{11}$ Increased plasma VEGF levels have been reported in CKD or ESRD patients underwent HD. ${ }^{12,13}$ In the literature, bilateral nephrectomy in mice has caused an extreme increase in plasma VEGF. ${ }^{14}$ On the contrary, VEGF levels of HD patients were not higher than the control group in our study, unlikely to the literature. This may be due to the nonspecific increases in VEGF levels because of inflammation, coagulation or such other biological processes. Tomas Lenz et al ${ }^{15}$ were not able to show a significant correlation between VEGF and sVEGFR-1 in diabetic patients with reduced renal function. We have found a significant correlation between VEGF and sVEGFR-1. From this point of view, VEGF reduction by an increase in sVEGFR-1 may be one of the causes of decreased angiogenesis in
Table 1 - Comparison of demographic and laboratory features, VEGF, and sVEGFR-1 levels of ESRD group and control group.

\begin{tabular}{|c|c|c|c|}
\hline $\begin{array}{l}\text { Demographic and } \\
\text { laboratory features }\end{array}$ & $\begin{array}{l}\text { ESRD } \\
(\mathrm{n}=38)\end{array}$ & $\begin{array}{l}\text { Control } \\
(\mathrm{n}=35)\end{array}$ & $P$-value \\
\hline Age (years) & $70.08 \pm 11.91$ & $70.69 \pm 9.54$ & 0.812 \\
\hline Gender (F/M) & $21 / 17$ & $16 / 19$ & $0.415^{* *}$ \\
\hline BMI $\left(\mathrm{kg} / \mathrm{m}^{2}\right)$ & $26.28 \pm 4.91$ & $27.99 \pm 4.30$ & 0.119 \\
\hline Glucose (fasting) (mg/dL) & $109.79 \pm 35.70$ & $98.51 \pm 17.79$ & 0.161 \\
\hline Urea $(\mathrm{mg} / \mathrm{dL})$ & $138.76 \pm 66.74$ & $32.38 \pm 8.36$ & $<0,001$ \\
\hline Creatinine $(\mathrm{mg} / \mathrm{dL})$ & $5.06 \pm 2.17$ & $0.88 \pm 0.20$ & $<0.001$ \\
\hline $\mathrm{eGFR}\left(\mathrm{mL} / \mathrm{min} / 1.73 \mathrm{~m}^{2}\right)$ & $11.51 \pm 5.71$ & $77.00 \pm 15.55$ & $<0,001$ \\
\hline Hemoglobin $(\mathrm{g} / \mathrm{dL})$ & $10.6(7.04-14.4)$ & $13.25(9.3-16.23)$ & $<0.001^{*}$ \\
\hline Platelet $\left(10^{3} / \mathrm{mm}^{3}\right)$ & $228(41-507)$ & $274(111-394)$ & $0.108^{*}$ \\
\hline White blood cell $\left(/ \mathrm{mm}^{3}\right)$ & $9118 \pm 4046$ & $6014 \pm 1759$ & $<0.001$ \\
\hline Sedimentation $(\mathrm{mm} / \mathrm{h})$ & $28.95 \pm 24.01$ & $20.26 \pm 14.66$ & 0.064 \\
\hline CRP (mg/L) & $1.89 \pm 0.93$ & $1.39 \pm 1.06$ & 0.073 \\
\hline Albumin (g/dL) & $3.11 \pm 0.67$ & $4.38 \pm 0.33$ & $<0.001$ \\
\hline HDL-C (mg/dL) & $39.21 \pm 11.27$ & $49.60 \pm 10.22$ & $<0.001$ \\
\hline LDH (IU/L) & $322(165-734)$ & $380(262-495)$ & $0.024^{*}$ \\
\hline Uric acid (mg/dL) & $6.57 \pm 2.43$ & $5.16 \pm 1.42$ & 0.004 \\
\hline Parathormone (ng/L) & $288.2 \pm 220.6$ & $57.61 \pm 9.56$ & $<0.001$ \\
\hline Calcium (g/dL) & $8.54 \pm 0.92$ & $9.65 \pm 0.54$ & $<0.001$ \\
\hline Phosphorus (g/dL) & $4.91 \pm 1.63$ & $3.18 \pm 0.34$ & $<0.001$ \\
\hline Magnesium (g/dL) & $2.19 \pm 0.28$ & $2.07 \pm 0.15$ & 0.028 \\
\hline sVEGFR-1 (ng/mL) & $0.217 \pm 0.135$ & $0.068 \pm 0.047$ & $<0.001$ \\
\hline VEGF (ng/mL) & $0.280 \pm 0.264$ & $0.321 \pm 0.210$ & 0.475 \\
\hline \multicolumn{4}{|c|}{$\begin{array}{l}\text { BMI - body mass index, CRP - C-reactive protein, eGFR - estimated } \\
\text { glomerular filtration rate, ESRD - end-stage renal disease, HDL - high- } \\
\text { density lipoprotein-cholesterol, LDH - lactate dehydrogenize, sVEGFR-1 } \\
\text { - soluble vascular endothelial growth factor receptor-1, VEGF - vascular } \\
\text { endothelial growth factor. Values are given as mean } \pm \text { standard deviation; } \\
\text { variables, which are not normally distributed, are given as medians } \\
\text { (minimum, maximum). }{ }^{*} \text { The result of mann-whitney U test according to } \\
\text { the median values, }{ }^{* *} \text { Result of Chi-square test }\end{array}$} \\
\hline
\end{tabular}

ESRD patients. Because we have also found sVEGFR-1 levels significantly higher in ESRD patients. We believe that it can be an important clinical sign in ESRD clinical course.

It was previously known that sVEGFR-1 was correlated with morbidity and mortality and was a potent indicator of disease severity in septic or seriously ill patients. ${ }^{16,17}$ In this regard, we believe that sVEGFR-1 is an important molecule in an aspect of ESRD pathogenesis and clinical course. In our study, the correlation analysis between VEGF and sVEGFR-1 was significantly negative. We speculate that a decreased level of sVEGFR-1 by increased level of VEGF is a physiological response to inflammation, designed to increase angiogenesis in ESRD patients. 
Table 2 - Comparison of VEGF and sVEGFR-1 levels in comorbidities and medications of ESRD patients.

\begin{tabular}{|c|c|c|c|c|c|c|c|}
\hline \multirow{2}{*}{$\begin{array}{l}\text { Comorbidities and } \\
\text { medications }\end{array}$} & \multirow[b]{2}{*}{$\mathrm{n}$} & \multicolumn{3}{|c|}{ VEGF } & \multicolumn{3}{|c|}{ sVEGFR-1 } \\
\hline & & Mean \pm SD & P1 & P2 & Mean \pm SD & P1 & P2 \\
\hline CAD (-) & 31 & $0.263 \pm 0.24$ & \multirow[t]{2}{*}{0.665} & & $0.213 \pm 0.13$ & \multirow[t]{2}{*}{0.418} & \\
\hline $\mathrm{CAD}(+)$ & 7 & $0.354 \pm 0.34$ & & 0.800 & $0.234 \pm 0.13$ & & $<0.001$ \\
\hline $\mathrm{HT}(-)$ & 16 & $0.304 \pm 0.30$ & \multirow[t]{2}{*}{0.701} & & $0.215 \pm 0.10$ & \multirow[t]{2}{*}{0.605} & \\
\hline $\mathrm{HT}(+)$ & 22 & $0.262 \pm 0.23$ & & 0.184 & $0.218 \pm 0.15$ & & $<0.001$ \\
\hline $\mathrm{HF}(-)$ & 26 & $0.282 \pm 0.25$ & \multirow[t]{2}{*}{0.753} & & $0.220 \pm 0.14$ & \multirow[t]{2}{*}{0.838} & \\
\hline $\mathrm{HF}(+)$ & 12 & $0.297 \pm 0.27$ & & 0.242 & $0.210 \pm 0.11$ & & $<0.001$ \\
\hline ACE inh $(-)$ & 35 & $0.282 \pm 0.26$ & \multirow[t]{2}{*}{0.551} & & $0.194 \pm 0.08$ & \multirow[t]{2}{*}{0.159} & \\
\hline ACE inh (+) & 3 & $0.254 \pm 0.25$ & & 0.343 & $0.481 \pm 0.31$ & & 0.007 \\
\hline ARB (-) & 35 & $0.289 \pm 0.26$ & \multirow[t]{2}{*}{0.465} & & $0.222 \pm 0.13$ & \multirow[t]{2}{*}{0.417} & \\
\hline ARB (+) & 3 & $0.173 \pm 0.17$ & & 0.223 & $0.156 \pm 0.06$ & & 0.016 \\
\hline ASA (-) & 31 & $0.247 \pm 0.24$ & \multirow[t]{2}{*}{0.118} & & $0.215 \pm 0.13$ & \multirow[t]{2}{*}{0.735} & \\
\hline ASA (+) & 7 & $0.424 \pm 0.32$ & & 0.578 & $0.227 \pm 0.13$ & & $<0.001$ \\
\hline Enoxaparin(-) & 28 & $0.296 \pm 0.27$ & \multirow[t]{2}{*}{0.654} & & $0.215 \pm 0.10$ & \multirow[t]{2}{*}{0.220} & \\
\hline Enoxaparin(+) & 10 & $0.234 \pm 0.22$ & & 0.140 & $0.222 \pm 0.19$ & & $<0.001$ \\
\hline B.Blocker (-) & 29 & $0.246 \pm 0.24$ & \multirow[t]{2}{*}{0.154} & & $0.212 \pm 0.14$ & \multirow[t]{2}{*}{0.192} & \\
\hline B.Blocker $(+)$ & 9 & $0.390 \pm 0.29$ & & 0.611 & $0.235 \pm 0.11$ & & $<0.001$ \\
\hline CCB (-) & 30 & $0.287 \pm 0.26$ & \multirow[t]{2}{*}{0.816} & & $0.237 \pm 0.14$ & \multirow[t]{2}{*}{0.012} & \\
\hline $\mathrm{CCB}(+)$ & 8 & $0.254 \pm 0.26$ & & 0.190 & $0.141 \pm 0.04$ & & $<0.001$ \\
\hline rhEPO (-) & 34 & $0.246 \pm 0.24$ & \multirow[t]{2}{*}{0.025} & & $0.220 \pm 0.14$ & \multirow[t]{2}{*}{0.617} & \\
\hline rhEPO (+) & 4 & $0.567 \pm 0.28$ & & 0.064 & $0.190 \pm 0.02$ & & 0.004 \\
\hline OAD (-) & 28 & $0.292 \pm 0.25$ & \multirow[t]{2}{*}{0.436} & & $0.206 \pm 0.14$ & \multirow[t]{2}{*}{0.037} & \\
\hline OAD (+) & 10 & $0.246 \pm 0.24$ & & 0.096 & $0.248 \pm 0.11$ & & $<0.001$ \\
\hline Insulin (-) & 31 & $0.318 \pm 0.27$ & \multirow[t]{2}{*}{0.033} & & $0.202 \pm 0.10$ & \multirow[t]{2}{*}{0.169} & \\
\hline Insulin (+) & 7 & $0.111 \pm 0.10$ & & 0.004 & $0.284 \pm 0.21$ & & $<0.001$ \\
\hline \multicolumn{8}{|c|}{$\begin{array}{c}\text { ACE inh - angiotensin-converting enzyme inhibitor, ARB - angiotensin II receptor blocker, B.Blocker - beta blocker, ASA - acetylsalicylic acid, } \\
\text { CAD - coronary artery disease, CCB - calcium channel blockers, ESRD - end-stage renal disease, HF - heart failure, HT - hypertension, OAD - oral } \\
\text { antidiabetic, rhEPO - recombinant human erythropoietin, sVEGFR-1 - soluble vascular endothelial growth factor receptor-1, VEGF - vascular } \\
\text { endothelial growth factor, P1 - Comparison of the accompanying diseases or medications used in heart failure group, P2 - Comparison with the control } \\
\text { group, values were given as mean } \pm \text { standard deviation }\end{array}$} \\
\hline
\end{tabular}

The age, gender, and the BMI of the 2 groups were similar. The average age was $70.08 \pm 11.91$ in patients group. The increased incidence of ESRD in elderly is compatible with the literature. ${ }^{18}$

As sVEGFR-1 is expressed in both endothelial cells and macrophages, VEGFR-1 has been related to inflammation. ${ }^{19}$ With this knowledge, we can see increasing of sVEGFR-1 by increasing levels of WBCs. We have reported a significant and positive correlation between WBC and sVEGFR-1.

The CKD is an independent risk factor for the development of CAD, and for the everity of CAD. ${ }^{20}$ It is known that incidence of CAD increases in renal osteodystrophy in CKD patients, most probably by one of the mechanisms of a decrease in the angiogenic process. The correlation analysis between parathormone and sVEGFR-1 was significantly positive. We have also found a positive correlation between phosphorus and sVEGFR-1, and a negative correlation between calcium and sVEGFR-1. The levels of calcium and phosphorus are similar to the levels in renal osteodystrophy patients. Qunying Guo et $\mathrm{al}^{21}$ found significant associations between sVEGFR-1 and cardiac disease. The sVEGFR-1 may be one of the mechanisms of decrease of angiogenesis in CKD patients with renal osteodystrophy. The positive correlation between phosphorus and sVEGFR-1 is a new finding among the studies in this area. Also, the correlation between sVEGFR-1 and albumin, HDL-C, calcium were found to be significantly negative for the first time.

Tomas Lenz et $\mathrm{al}^{22}$ suggested that in vivo erythropoietin does not affect the functionality and/ or production of components of the VEGF system in diabetics with CKD. According to this study, the effects of exogenous rhEPO upon VEGF and/or the sVEGFR-1 have not been evaluated before. In the present study, the average VEGF level of ESRD patients using rhEPO was significantly higher than the ESRD patients not using rhEPO. The average sVEGFR-1 level of ESRD patients using rhEPO was not significantly different from the ESRD patients not using rhEPO. Further investigations with more participants may reveal significant results 
Table 3 - Correlation analyses of VEGF and sVEGFR-1 levels with other clinical features in ESRD group $(\mathrm{n}=38)$.

\begin{tabular}{lcccc}
\hline Clinical features & \multicolumn{2}{c}{ VEGF } & \multicolumn{2}{c}{ sVEGFR-1 } \\
& r & $P$-value & r & $P$-value \\
\hline VEGF & 1 & & -0.246 & 0.036 \\
sVEGFR-1 & -0.246 & 0.036 & 1 & \\
White Blood Cell & -0.029 & 0.809 & 0.371 & 0.001 \\
Hemoglobin & 0.166 & 0.161 & -0.479 & $<0.001$ \\
Urea & -0.038 & 0.751 & 0.340 & 0.003 \\
Creatinine (Predialysis) & -0.022 & 0.850 & 0.401 & $<0.001$ \\
GFR & 0.117 & 0.323 & -0.548 & $<0.001$ \\
Albumin & 0.053 & 0.654 & -0.505 & $<0.001$ \\
HDL-C & 0.030 & 0.801 & -0.287 & 0.014 \\
LDH & 0.119 & 0.315 & 0.000 & 0.999 \\
Uric acid & -0.125 & 0.291 & 0.215 & 0.068 \\
Parathormone & 0.112 & 0.346 & 0.322 & 0.005 \\
Calcium & 0.101 & 0.395 & -0.259 & 0.027 \\
Phosphorus & 0.002 & 0.986 & 0.360 & 0.002 \\
Magnesium & -0.046 & 0.702 & 0.150 & 0.205 \\
\hline \multicolumn{1}{c}{ eGFR - estimated glomerular filtration rate, HDL-C - high- } \\
density lipoprotein-cholesterol, LDH - lactate dehydrogenase, \\
$\quad$ sVEGFR-1 - soluble vascular endothelial growth factor \\
$\quad$ receptor-1, VEGF - vascular endothelial growth factor \\
\hline \multicolumn{5}{c}{}
\end{tabular}

about sVEGFR-1. The fact that rhEPO has been given with remarkable clinical benefit to patients with preterminal and terminal renal failure, now makes it likely that convenient effects on the angiogenesis may be a relevant effect of this agent. Further investigations may be needed in this area. Tartare et $\mathrm{al}^{23} \&$ Miele et $\mathrm{al}^{24}$ have declarated that VEGF induction by insulin treatment occurs via different signaling pathways. In our study, we found that average VEGF level of ESRD patients using insulin was significantly lower than the ESRD patients not using insulin contrary to literature. This result may show that insulin treatment in diabetic patients with ESRD may decrease angiogenesis via the reduction of VEGF. The average sVEGFR-1 level of ESRD patients using CCB was significantly lower than the ESRD patients not using CCB. All of our patients were using dihydropyridine CCB. Allanore et $\mathrm{al}^{25}$ reported that nifedipine concentration did not affect the VEGF and sVEGFR-1 levels. Our finding may reveal a positive effect of $\mathrm{CCB}$ on angiogenesis in patients under HD treatment. Further investigations are needed in this area.

Study limitations. This study is based on a limited number of patients and thus, cannot ascertain whether these findings can be applied to other patients with ESRD. Due to this limitation the associations with clinical findings such as demographic features, laboratory findings, comorbidities, and medications have been considered as secondary objectives. Further studies with more participants should be performed. But evaluating both of these agents (VEGF and sVEGFR-1) concurrently makes it easy to evaluate the balance of angiogenic/anti-angiogenic factors in patients with ESRD.

In conclusion, sVEGFR-1 levels of ESRD patients are significantly higher than the control group. We found novel associations among the sVEGFR-1 and VEGF levels and medications. Especially our finding of rhEPO and VEGF illuminates a reasonable positive effect of rhEPO on angiogenesis. We report novel associations between VEGF, sVEGFR-1, insulin and CCB medication. Accordingly, larger clinical studies will be necessary for confirmation of these findings.

Acknowledgment. We would like to thank our patients and their families who participated in the research helpfully and devotedly without expecting material compensation. We would like to thank Scribendi for the professional English language and scientific editing.

\section{References}

1. National Kidney Foundation. K/DOQI clinical practice guidelines for chronic kidney disease: evaluation, classification, and stratification. Am J Kidney Dis 2002; 39 (2 Suppl 1): S1-S266.

2. Levey AS, Stevens LA, Coresh J. Conceptual model of CKD: applications and implications. Am J Kidney Dis 2009; 53: S4.

3. Abboud H, Henrich WL. Clinical practice. Stage IV chronic kidney disease. N Engl J Med 2010; 362: 56.

4. Eremina V, Baelde HJ, Quaggin SE. Role of the VEGF--a signaling pathway in the glomerulus: evidence for crosstalk between components of the glomerular filtration barrier. Nephron Physiol 2007; 106: 32-37.

5. Ferrara N. Role of vascular endothelial growth factor in regulation of physiological angiogenesis. Am J Physiol Cell Physiol 2001; 280: C1358-C1366.

6. Ferrara N, Davis-Smyth T. The biology of vascular endothelial growth factor. Endocr Rev 1997; 18: 4-25.

7. Wada T, Jesmin S, Gando S, Yanagida Y, Mizugaki A, Sultana $\mathrm{SN}$, et al. Angiogenic factors and their soluble receptors predict organ dysfunction and mortality in post-cardiac arrest syndrome. Crit Care 2012; 16: R171.

8. Kendall RL, Wang G, Thomas KA. Identification of a natural soluble form of the vascular endothelial growth factor receptor, FLT-1, and its heterodimerization with KDR. Biochem Biophys Res Commun 1996; 226: 324-328.

9. Kaza E, Ablasser K, Poutias D, Griffiths ER, Saad FA, Hofstaetter JG, et al. Up-regulation of soluble vascular endothelial growth factor receptor-1 prevents angiogenesis in hypertrophied myocardium. Cardiovasc Res 2011; 89: 410-418.

10. Hornig C, Barleon B, Ahmad S, Vuorela P, Ahmed A, Weich HA. Release and complex formation of soluble VEGFR-1 from endothelial cells and biological fluids. Lab Invest 2000; 80: 443-454. 
11. Di Marco GS, Reuter S, Hillebrand U, Amler S, König M, Larger E, et al. The soluble VEGF receptor sFlt1 contributes to endothelial dysfunction in CKD. J Am Soc Nephrol 2009; 20: 2235-2245.

12. Harper SJ, Downs L, Tomson CR, Dwight JS, Bolton C. Elevated plasma vascular endothelial growth factor levels in non-diabetic predialysis uraemia. Nephron 2002; 90: 341-343.

13. Pawlak K, Pawlak D, Myśliwiec M. Possible association between circulating vascular endothelial growth factor and oxidative stress markers in hemodialysis patients. Med Sci Monit 2006; 12: CR181-CR185.

14. Doi K, Leelahavanichkul A, Hu X, Sidransky KL, Zhou H, Qin Y, et al. Pre-existing renal disease promotes sepsis-induced acute kidney injury and worsens outcome. Kidney Int 2008; 74: 1017-1025.

15. Lenz T, Gauer S, Weich HA, Haak T, Bergner R, Gossmann J. Vascular endothelial growth factor and its soluble receptor, Flt-1, are not correlated to erythropoietin in diabetics with normal or reduced renal function. Nephrology (Carlton) 2005; 10: 84-89.

16. Wada T, Jesmin S, Gando S, Sultana SN, Zaedi S, Yokota H. Using angiogenic factors and their soluble receptors to predict organ dysfunction in patients with disseminated intravascular coagulation associated with severe trauma. Crit Care 2012; 16: R63.

17. Yang KY, Liu KT, Chen YC, Chen CS, Lee YC, Perng RP, et al. Plasma soluble vascular endothelial growth factor receptor-1 levels predict outcomes of pneumonia-related septic shock patients: a prospective observational study. Crit Care 2011; 15: R11.

18. Abboud H, Henrich WL. Clinical practice. Stage IV chronic kidney disease. N Engl J Med 2010; 362: 56-65.

19. Clauss M, Weich H, Breier G, Knies U, Röckl W, Waltenberger J, et al. The vascular endothelial growth factor receptor Flt-1 mediates biological activities. Implications for a functional role of placenta growth factor in monocyte activation and chemotaxis. J Biol Chem 1996; 271: 17629-17634.
20. Sarnak MJ, Levey AS, Schoolwerth AC, Coresh J, Culleton B, Hamm LL, et al. Kidney disease as a risk factor for development of cardiovascular disease: a statement from the American Heart Association Councils on Kidney in Cardiovascular Disease, High Blood Pressure Research, Clinical Cardiology, and Epidemiology and Prevention. Circulation 2003; 108: 2154-2169.

21. Guo Q, Carrero JJ, Yu X, Bárány P, Qureshi AR, Eriksson $\mathrm{M}$, et al. Associations of VEGF and its receptors sVEGFR-1 and -2 with cardiovascular disease and survival in prevalent haemodialysis patients. Nephrol Dial Transplant 2009; 24: 3468-3473.

22. Lenz T, Gauer S, Weich HA, Haak T, Bergner R, Gossmann J. Vascular endothelial growth factor and its soluble receptor, Flt-1, are not correlated to erythropoietin in diabetics with normal or reduced renal function. Nephrology (Carlton) 2005; 10: 84-89.

23. Tartare S, Mothe I, Kowalski-Chauvel A, Breittmayer JP, Ballotti R, Van Obberghen E. Signal transduction by a chimeric insulin-like growth factor-1 (IGF-1) receptor having the carboxyl-terminal domain of the insulin receptor. $J$ Biol Chem 1994; 269: 11449-11455.

24. Miele C, Rochford JJ, Filippa N, Giorgetti-Peraldi S, Van Obberghen E. Insulin and insulin-like growth factor-I induce vascular endothelial growth factor mRNA expression via different signaling pathways. J Biol Chem 2000; 275: 2169521702.

25. Allanore $\mathrm{Y}$, Borderie D, Lemaréchal $\mathrm{H}$, Ekindjian OG, Kahan A. Nifedipine decreases sVCAM-1 concentrations and oxidative stress in systemic sclerosis but does not affect the concentrations of vascular endothelial growth factor or its soluble receptor 1. Arthritis Res Ther 2004; 6: R309-R314. 